\title{
Men's Oppressive Beliefs Predict Their Breast Size Preferences in Women
}

\author{
Viren Swami • Martin J. Tovée
}

Received: 31 January 2012 / Revised: 19 April 2012/ Accepted: 15 October 2012 / Published online: 15 February 2013

(C) Springer Science+Business Media New York 2013

\begin{abstract}
Previous studies of men's breast size preferences have yielded equivocal findings, with studies variously indicating a preference for small, medium, or large breasts. Here, we examined the impact of men's oppressive beliefs in shaping their female breast size ideals. British White men from the community in London, England $(N=361)$ viewed figures of women that rotated in $360^{\circ}$ and varied in breast size along five levels. They then rated the figure that they found most physically attractive and also completed measures assessing their sexist attitudes and tendency to objectify women. Results showed that medium breasts were rated most frequent as attractive $(32.7 \%)$, followed by large (24.4\%) and very large (19.1\%) breasts. Further analyses showed that men's preferences for larger female breasts were significantly associated with a greater tendency to be benevolently sexist, to objectify women, and to be hostile towards women. These results were discussed in relation to feminist theories, which postulate that beauty ideals and practices in contemporary societies serve to maintain the domination of one sex over the other.
\end{abstract}

Keywords Breast size - Physical attractiveness . Oppressive beliefs $\cdot$ Sexism $\cdot$ Objectification

V. Swami ( $\square)$

Department of Psychology, University of Westminster, 309 Regent Street, London W1B 2UW, UK

e-mail:v.swami@westminster.ac.uk

V. Swami

Department of Psychology, HELP University College, Kuala Lumpur, Malaysia

M. J. Tovée

School of Psychology, Newcastle University,

Newcastle-upon-Tyne, UK

\section{Introduction}

The topic of physical attractiveness remains one of enduring fascination for both scholars and the wider community (for reviews, see Buss, 2003; Swami, 2007; Swami \& Furnham, 2008; Swami \& Harris, 2012). In terms of women's attractiveness, much of the available scholarly literature has focused either on facial attractiveness (see Rhodes, 2006) or on the relative utility of the waist-to-hip ratio versus overall body size in shaping men's attractiveness judgments (see Swami \& Salem, 2011). By contrast, much less research has focused on other female sexual traits that influence men's judgments of attractiveness, including hair color (e.g., Swami \& Barrett, 2011), leg length (e.g., Swami, Einon, \& Furnham, 2006), and breasts. The lack of focus on female breasts, at least relative to other morphological traits, is particularly surprising given the sexual significance of breasts in many societies (Dettwyler, 1995; Koff \& Benavage, 1998).

Indeed, recent eye-tracking studies have shown that, when presented with frontal images of women, men spend more time looking at the breasts and upper-body than any other region (Cornelissen, Hancock, Kiviniemi, George, \& Tovée, 2009; Dixson, Grimshaw, Linklater, \& Dixson, 2011). Of course, female breasts vary along many different dimensions that may affect men's attractiveness judgments, including size, shape, asymmetry, areola size, and pigmentation (Dixson et al., 2010; Manning, Scutt, Whitehouse, \& Leinster, 1997; Zelazniewicz \& Pawłowski, 2010). Nevertheless, size is perhaps the most public of these variables (e.g., Lynn, 2009) and is also the principal way in which women's breasts are embodied and objectified in popular culture (Carter, 1996; Mazur, 1986; Tantleff-Dunn, 2001). Not surprisingly, then, a number of theories have been postulated to explain the evolutionary significance of prominent female breasts.

Some suggestions have focused on the functional role of breasts, including as milk storage organs during periods of 
resource scarcity, fat reserves for breast-feeding babies, or mechanisms of heat stress avoidance (for a review, see Einon, 2007). However, these arguments appear to have little contemporary support (Barber, 1995; Pond, 1998) and alternative explanations have been proposed, including the possibility that breast enlargement occurred as a by-product of gluteofemoral fat deposition (Pawłowski, 1999). The most widely-accepted possibility is that permanent female breasts evolved under runaway sexual selection, possibly as a sign of nulliparity, age, or sexual maturity (Barber, 1995; Gallup, 1982; Marlowe, 1998; Zelazniewicz \& Pawłowski, 2010).

Even so, studies examining men's breast size preferences have not yielded consistent findings. Thus, studies using linedrawings of the female figure have suggested that men have a preference for small breasts (Furnham \& Swami, 2007) while other studies have reported a preference for medium (Horvath, 1981; Kleinke \& Staneski, 1980; Tantleff-Dunn, 2002; Wiggins, Wiggins, \& Conger, 1968) or large breasts (Furnham, Dias, \& McClelland, 1998; Gitter, Lomranz, Saxe, \& Bar-Tal, 1983; Singh \& Young, 1995). At least one study has also reported that breast size does not independently account for men's attractiveness judgments (Furnham, Swami, \& Shah, 2006). Possible explanations for these equivocal findings include differences in presentation format (e.g., frontal- vs. sideview), which is known to affect judgments (Zelazniewicz \& Pawłowski, 2010) and, more importantly, the poor ecological validity of line-drawn stimuli (cf. Swami, 2008; Tovée \& Cornelissen, 2001). When more ecologically valid stimulus sets are used, including photographic and computer-generated images, there appears to be a preference for medium-to-large breasts (Dixson et al., 2010, 2011; Zelazniewicz \& Pawłowski, 2010).

In addition, studies have not fully examined the impact of cultural membership on breast size preferences. Thus, some studies have indicated that there are cross-cultural differences in what is perceived as the ideal breast size (e.g., Dixson et al., 2010; Swami, Jones, Einon, \& Furnham, 2009). In a similar vein, it is also likely that, within cultures, there will be some inter-individual differences in breast size ideals, as has been postulated (Swami \& Tovée, 2009) and empirically demonstrated (Swami, Buchanan, Furnham, \& Tovée, 2008; Swami et al., 2010b; Swami, Miller, Furnham, Penke, \& Tovée, 2008) in relation to men's female body size ideals (for a review, see Swami, 2011). Thus, in a recent study, Zelazniewicz and Pawłowski (2010) compared the breast size ideals of sociosexually unrestricted and restricted men (that is, men pursuing low-commitment, transient sexual relationships with multiple partners vs. men pursuing a single, high-investment relationship). Zelazniewicz and Pawłowski reported that sociosexually unrestricted men rated photographs of larger female breasts as more physically attractive than did restricted men.

Studies examining breast size ideals and observer psychological traits remain in their infancy and, in the present study, we sought to extend this literature by focusing on men's oppressive beliefs. Our perspective was derived from feminist psychology, which posits that corporeal experiences are, in part, shaped by patriarchal structures in society, gendered identities, and power relationships between women and men (Bartky, 1990; Bordo, 1993; Dworkin, 1974; Wolf, 1990). That is, feminist theorists argue that beauty ideals and practices are engendered and used by male-dominated societies to ensure that women's attention is shifted away from their real competencies and toward superficial aspects associated with their appearance. This perspective suggests that membership in patriarchal societies gradually socializes individuals to adopt physical ideals that are associated with enhanced masculinity or femininity (Swami \& Voracek, in press). Practically, however, there will likely be individual differences in the endorsement of oppressive beliefs (usually operationalized as sexist attitudes and objectification of others), which allows scholars to examine the associations between those beliefs and attractiveness ideals (Forbes, Collinsworth, Jobe, Brain, \& Wise, 2007).

There is now growing evidence in support of the suggestion that men's oppressive beliefs shape their attractiveness preferences. For example, in one study, Forbes et al. (2007) reported that men who more strongly endorsed sexist attitudes were more likely to believe that it was important for women to be thin. This finding was extended by Swami et al. (2010a), who reported that men's greater sexist attitudes and tendency to objectify others was associated with a stronger tendency to rate thinner female figures as being maximally attractive. Related work has shown that endorsement of traditional malerole attitudes (Salska et al., 2008; Swami et al., 2008), sexist attitudes, and objectification tendency (Swami et al., 2010a) were associated with a male preference to be in relationships where the man was taller than the woman. Finally, men's oppressive beliefs were also associated with greater endorsement of cosmetic use among women (Swami et al., 2010a).

In short, then, it has been proposed that men's greater endorsement of oppressive beliefs are associated with a preference for traditional, feminine beauty ideals, particularly those that are difficult to attain or that require constant work on the body. Breast size is a prima facie candidate of such an ideal, but, to our knowledge, no previous study has examined associations between breast size ideals and oppressive beliefs. Even so, there are reasons to expect that greater endorsement of oppressive beliefs will be associated with a male preference for larger female breasts. For example, large breasts are associated with stronger perceptions of femininity and are an important signifier of women's sexualization and womanhood (Ford \& Beach, 1951; Millsted \& Frith, 2003). Just as important, the female breast has become an important site of objectification in many socioeconomically developed societies (Seifert, 2005; Ward, Merriwhether, \& Caruthers, 2006) and the fetishization of large breasts 
appears to be an important component of media aimed at hegemonically masculine men (Gerald \& Potvin, 2009). Furthermore, and consistent with feminist theory, women are increasingly dissatisfied with their breasts, with the majority wanting to have larger breasts (e.g., Forbes, Jobe, \& Revak, 2006; Harrison, 2003; Jacobi \& Cash, 1994; Tantleff-Dunn \& Thompson, 2000). Based on this evidence, it might be suggested that, to the extent that larger female breasts are associated with perceptions of sexualization and femininity, men's oppressive beliefs will be associated with a preference for larger breasts.

In the present study, then, we examined associations between men's oppressive beliefs, operationalized as sexist attitudes and a tendency to objectify women, and their female breast size ideals. In order to avoid the limitations associated with linedrawn stimuli and because viewing angle is known to affect preferences (Zelazniewicz \& Pawłowski, 2010), we developed and utilized a novel set of computer-generated stimuli that rotated and thus provided a $360^{\circ}$ view of the stimuli. Earlier work has suggested that this method of presenting stimuli improves ecological validity and also overcomes limitations of singleview presentation methods that may accentuate specific physical traits (Smith, Cornelissen, \& Tovée, 2007). Based on the above review of the literature, we predicted that stronger endorsement of sexist attitudes and a greater tendency to objectify women would be associated with a stronger preference for larger female breasts among men.

\section{Method}

\section{Participants}

Participants in this study were initially 440 men recruited from the community in London, England. However, because ethnic identity is known to affect breast size perceptions (Swami et al., 2009) we excluded all participants who did not self-report as being of British White descent $(n=52)$. From the remaining sample, we further excluded participants who self-reported as being gay $(n=8)$ or bisexual $(n=12)$, or who preferred not to disclose their sexual orientation $(n=7)$. Thus, the final sample consisted of 361 British White men, who ranged in age from 18 to 68 years $(M=30.22, S D=9.87)$. In terms of educational qualifications, $27.5 \%$ had General Certificates of Secondary Education (minimum school-leavers' qualifications), $29.3 \%$ had Advanced Level (A-Level) General Certificates of Education, $26.3 \%$ had an undergraduate degree, 9.7\% had a postgraduate degree, and $7.2 \%$ had some other qualification. A total of $42.1 \%$ of participants were single, $33.2 \%$ were in a dating relationship, $18.6 \%$ were married, and the remainder had some other marital status.
Measures

Stimuli

The stimuli were created in an interactive three-dimensional (3D) modeling software, Daz Studio 3.1 (www.Daz3d.com), which allows the creation of photo-realistic 3D models. The female 3D model used was Victoria 4.2, with the Lana elite skin texture, the Victoria 4 Bikini, and Glamour Hair V4. The breast was modified using the breast size dimension on the Body morphs ++ add-on package. The bust size was set at 5 -levels, $-100,-50,0,50$, and 100 on the breast size slider. The body rotated through $360^{\circ}$ in $5^{\circ}$ steps using the aniMate 2 package for Daz Studio. The animation was rendered in 24-bit color and in $685 \times 895$ pixel resolution. It was exported as a 30-frames-per-second AVI. The stimuli were then presented concurrently and simultaneously on 13-inch laptop computers in ascending order (see Fig. 1). Participants were asked to rate the figure that they found most physically attractive, where 1 represented the figure with very small breasts and 5 represented the figure with very large breasts.

\section{Sexist Attitudes}

We measure sexist attitudes using three different scales that measure distinct aspects of sexism. First, we used the Hostility Towards Women Scale (HTWS) (Lonsway \& Fitzgerald, 1995) to measure explicit hostility towards women (sample item: "I feel that many times women flirt with men just to tease them or hurt them"). The HTWS is a 10-item scale on which items were rated on a 7-point Likert-type scale $(1=$ Strongly disagree, $7=$ Strongly agree). An overall HTWS score was computed as the mean of all 10 items, with higher scores representing more hostile attitudes toward women. Lonsway and Fitzgerald reported that the HTWS has acceptable reliability and good construct validity. In the present study, Cronbach's $\alpha$ for this scale was .88 .

Second, we included the 25-item Attitudes Toward Women Scale (AWS) (Spence, Helmreich, \& Stapp, 1978), which provides a measure of sexist attitudes about the relationships between women and men (Thompson, Pleck, \& Ferrera, 1992; sample item: "Intoxication among women is worse than intoxication among men"). Items on this scale were rated on a 4-point Likert-type scale (1=Agree strongly, $4=$ Disagree strongly) and an overall score was computed as the mean of all items. In its original form, higher scores indicate a more profeminist, egalitarian attitude, but in order to maintain consistency with other sexism scale, we reversed the AWS scores prior to analyses (higher scores reflect more sexist attitudes (cf. Swami et al., 2010a). Cronbach's $\alpha$ for this scale was .82.

Finally, we used the Benevolent Sexism (BS) subscale of Glick and Fiske's (1996) Ambivalent Sexism Inventory 

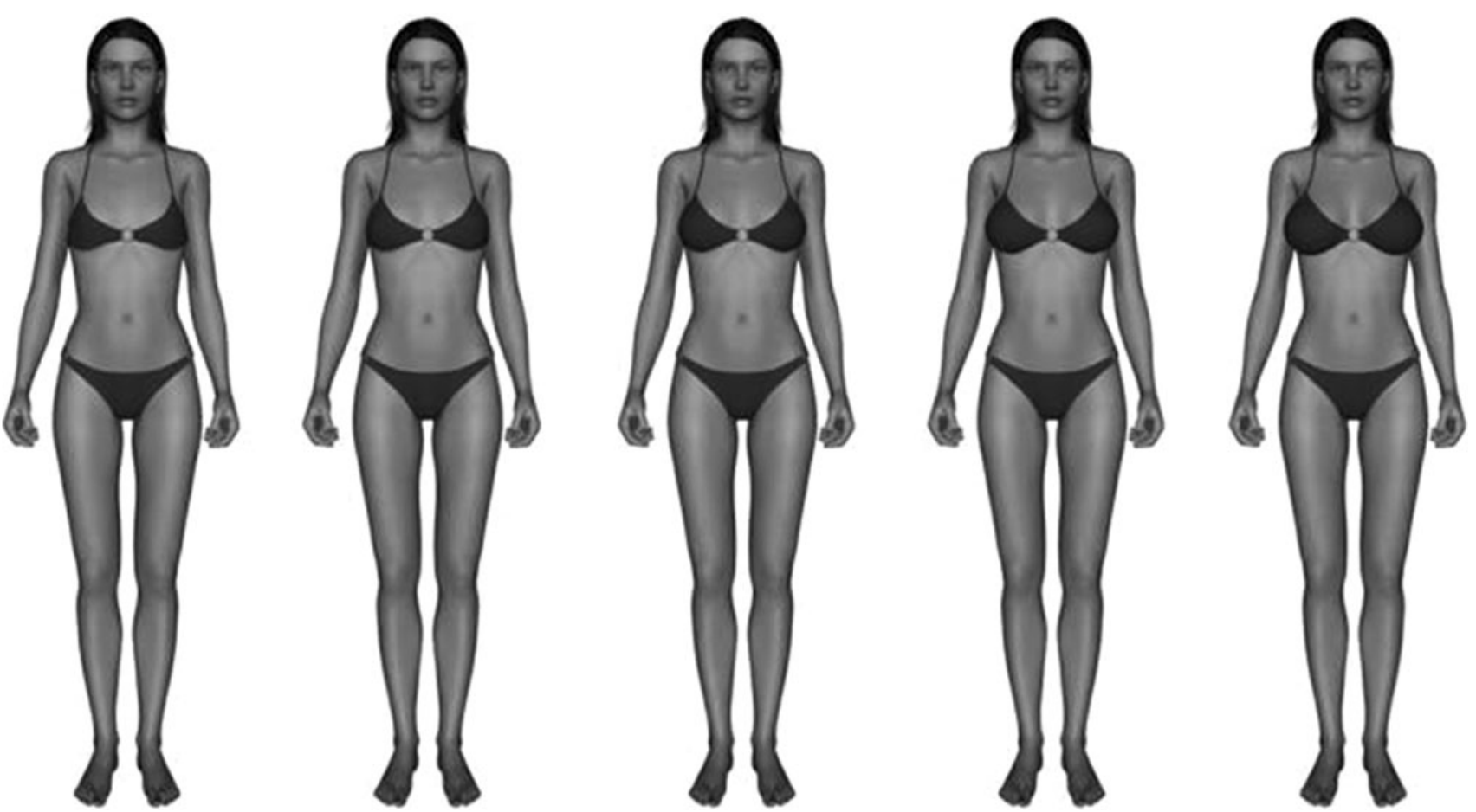

Fig. 1 Stimuli used in the present study. Note. During presentation, the stimuli were presented in color and were allowed to rotate in $360^{\circ}$

(ASI). The BS subscale is an 11-item measure that provides an index of the tendency to idealize women's traditional roles while simultaneously limiting them to subservient positions in society (sample item: "Every man ought to have a woman he adores"). All items on the BS subscale were rated on a 6-point Likert-type scale $(1=$ Disagree strongly, $6=$ Agree strongly) and an overall score was computed as the mean of all 11 items. Higher scores on this scale reflect more benevolently sexist attitudes. The ASI, including the BS subscale, has been shown to have good reliability and a good pattern of validity (Glick \& Fiske, 1996). In the present study, Cronbach's $\alpha$ for the BS subscale was .89.

\section{Objectification of Women}

To measure objectification of women, we used a modified version of the Self-Objectification Scale (SOS) (Frederickson, Roberts, Noll, Quinn, \& Twenge, 1998). In its original form, the SOS required participants to rank how important 10 body attributes were to their physical self-concept. In the present study, we used a version of the scale that was modified by Swami and Voracek (in press), in which participants were asked to rank the same attributes according to how important they were when judging at women. Previous studies have used similarly modified versions of the scale (e.g., Gurung \& Chrouser, 2007; Strelan \& Hargreaves, 2005; Swami et al., 2010a) and, consistent with objectification theory, have reported that objectification of others is associated with stronger sexist attitudes
(Swami et al., 2010a; Swami \& Voracek, in press). Five of the attributes are competence-based (e.g., strength) and five are appearance-based (e.g., weight). Each of these items was ranked on a scale ranging from 0 (Least impact) to 9 (Greatest impact). An overall objectification score was computed by subtracting the sum of competence-based items from the sum of appearancebased items, with higher scores indicating greater emphasis on appearance and, by extension, objectification of women (scores ranged from -25 to +25 ). Although it was not possible to compute an overall internal reliability coefficient, Hill and Fischer (2008) have suggested that that competence- and appearancebased sums should be negatively correlated (that is, individuals who prioritize appearance should denigrate competence). In the present study, the correlation between these sums was -.76.

Procedure

Once ethical approval for this study was obtained from the relevant university ethics committee, two research assistants recruited participants using convenience sampling from various public locations, including public libraries, parks, and train stations. The researchers approached potential participants in the catchment areas and invited them to take part in a study on physical attraction. Participants were initially given an information sheet, which contained brief information about the survey, the rights of participants, and contact information of the first author. Once participation had been agreed and participants had provided informed consent, they were taken to a quiet 
and private location in the catchment area and asked to view the breast size stimuli on a laptop computer and make their ratings on a paper-and-pencil survey. They then completed the scales described above, which were presented in a randomized order for each participant. All participants completed the survey individually, took part on a voluntary basis, and were not remunerated for participation. Once the surveys were returned, the research assistants verbally debriefed all participants. Participants were also provided with a debrief sheet containing further information about the study and contact details of the first author.

\section{Results}

Examining breast size ratings initially (see Fig. 2), we observed that the figure with medium breast size was selected most frequently as the most physically attractive (32.7\% of participants). However, there appeared to be a slight skew toward larger breast sizes, Kolmogorov-Smirnov statistic $=.17, d f=361, p<.001$ (skewness $=-.22$, kurtosis $=-.74$ ). As can be seen in Fig. 2, the figure with the large breast size was selected as the most physically attractive by $24.4 \%$ of the sample whereas the figure with the very large breast size was selected by $19.1 \%$ of the sample. By contrast, the figures with the small and very small breast sizes were selected by 15.5 and $8.3 \%$ of the sample, respectively.

Descriptive statistics for all study variables, as well as bivariate correlations between variables, are shown in Table 1. As can be seen, men's preference for larger breast sizes was significantly and positively correlated with hostility toward women, more sexist attitudes toward women, benevolent sexism, and objectification of women. The strength of these correlations was weakest for sexist attitudes as measured by the AWS $(r=.12)$

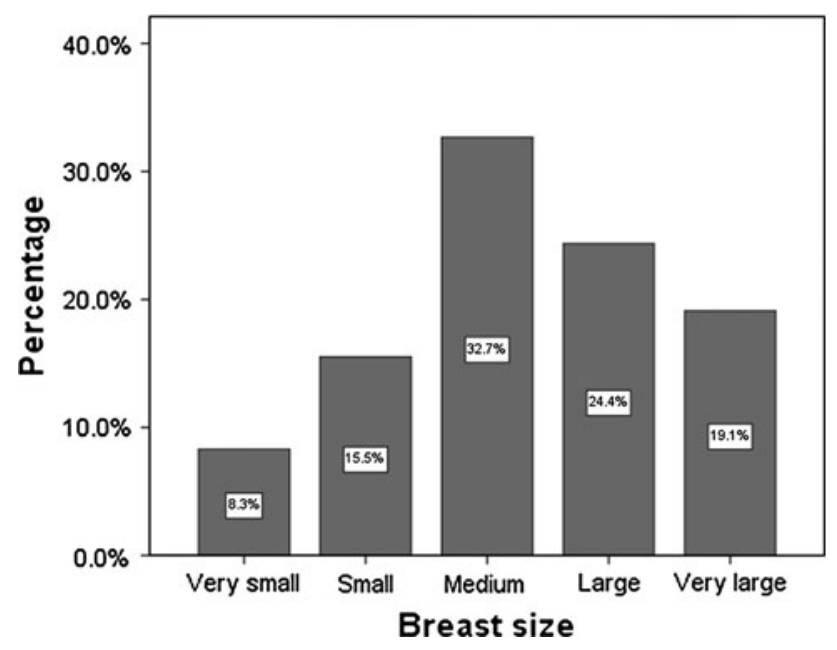

Fig. 2 Percentages of participants selecting each figure as the most physically attractive and strongest for benevolent sexism $(r=.58)$. There was also a significant and negative correlation between men's breast size ratings and age, such that younger men were more likely to rate larger breasts as being physically attractive. In addition, univariate analyses of variance (ANOVAs) showed that there were no significant between-group differences in breast size ratings as a function of education, $F(4,361)<1, \eta_{\mathrm{p}}^{2}<.01$, or relationship status, $F(3,361)=2.51, p=.058, \eta_{\mathrm{p}}^{2}=.02$.

Finally, we conducted a multiple linear regression in which breast size ratings was entered as the criterion variable and all other variables (HTWS, AWS, BS, objectification, and age) were entered simultaneously as predictor variables. Results showed that the regression was significant, $F(5,360)=38.60$, $p<.001$, Adj. $R^{2}=.34$. Collinearity diagnostics showed that all predictor variables had acceptable tolerance $(\geq .65)$ and variance inflation factors $(\leq 1.53)$. Of the variables entered into the model, benevolent sexism emerged as the strongest predictor $(\mathrm{b}=.59, \mathrm{SE}=.06, \beta=.55, t=10.33, p<.001)$. Other significant predictors were objectification of women $(\mathrm{b}=.33, \mathrm{SE}=$ $.18, \beta=.13, t=2.68, p<.001)$ and hostility toward women $(\mathrm{b}=.24, \mathrm{SE}=.14, \beta=.08, t=1.69, p=.047)$. On the other hand, sexism as measured on the AWS $(\mathrm{b}=.06, \mathrm{SE}=.07, \beta=$ $.05, t<1.0)$ and participant age $(\mathrm{b}=-.01, \mathrm{SE}=.01, \beta=-.01$, $t<1.0$ ) did not emerge as significant predictors.

\section{Discussion}

In the present study, we developed a new set of stimuli that rotated in $360^{\circ}$ to examine individual difference antecedents of men's ratings of the attractiveness of women's breast size. Our results showed that a greater likelihood of rating a larger breast size as physically attractive was predicted by men's oppressive beliefs. Specifically, we found that men who more strongly endorsed benevolently sexist attitudes toward women, who more strongly objectified women, and who were more hostile toward women idealized a large female breast size. Broadly speaking, the present results were consistent with previous studies indicating that men's oppressive beliefs are associated with their attractiveness ideals for women (Forbes et al., 2007; Swami et al., 2010a).

Our results showed that, of the variables included in our study, benevolent sexism was the strongest predictor of men's breast size ideals. Glick and Fiske (1996) have postulated that benevolently sexist men typically have a subjectively positive view of women. More specifically, these men are more likely to positively view traditionally feminine women and also ascribe masculine traits to non-traditional women. Applying these suggestions to the current results, it is arguable that benevolently sexist men perceived larger female breasts as attractive because larger breast size on a woman is associated with perceived femininity. In turn, heightened perceptions of femininity may mean that women with 
Table 1 Descriptive statistics and bivariate correlations between breast size ratings, sexist attitudes, objectification of women, and participant age

\begin{tabular}{|c|c|c|c|c|c|c|}
\hline & (1) & (2) & (3) & (4) & (5) & (6) \\
\hline (1) Breast size ratings & & $.24 * *$ & $.12^{*}$ & $.58 * *$ & $.38 * *$ & $-.13 *$ \\
\hline (2) Hostility toward women & & & $.53 * *$ & $.26 * *$ & $.28 * *$ & -.03 \\
\hline (3) Attitudes toward women & & & & $.32 * *$ & $.14 *$ & -.08 \\
\hline (4) Benevolent sexism & & & & & $.35^{* *}$ & .06 \\
\hline (5) Objectification of women & & & & & & $-.12 *$ \\
\hline \multicolumn{7}{|l|}{ (6) Participant age } \\
\hline$M$ & 3.33 & 2.41 & 2.89 & 3.08 & 10.32 & 30.22 \\
\hline$S D$ & 1.25 & 1.07 & 0.93 & 0.75 & 9.88 & 9.87 \\
\hline
\end{tabular}

Note. $N=361$

$* p<.05 ; * * p<.001$ (one-tailed)

larger breasts are perceived as submissive and less threatening to power relationships and gendered inequalities (cf. Sanchez, Kiefer, \& Ybarra, 2006). That is, insofar as breasts are an index of a gendered difference between women and men, benevolently sexist men may perceive larger breasts as "appropriate" for feminine women; in other words, in the view of benevolently sexism men, a feminine and submissive woman is likely to be someone with large breasts.

While it may be tempting to suggest that such attitudes are subjectively positive for the perceiver, and perhaps also for the receiver, it should be noted that the roots of benevolent sexism lie in traditional stereotypes of women and masculine domination (Glick \& Fiske, 1996). Indeed, Glick and Fiske have suggested that the consequences of benevolent sexism can sometimes be damaging. In terms of the present results, for example, it might be expected that benevolently sexist men will ascribe more negative gendered traits toward women with small breasts. Conversely, the benevolent sexist may focus on sexual aspects of women's bodies, believing that large breasts are a par excellence attribute of the feminine woman and that "breasts are for men" (Ward et al., 2006).

Conversely, hostile sexism and more sexist attitudes toward gendered role differentiation did not appear to be strongly associated with men's breast size ideals. Although both these variables were significantly associated with breast size ideals in our correlational analyses, only hostile sexism emerged as a significant predictor (although, even here, it was not a strong predictor). Based on this set of results, it might be argued that it is the tendency to view women in ways that are subjectively positive for the perceiver rather than to explicitly denigrate women that drives men's breast size preferences. Of course, both types of sexism stem from issues relating to power, gender identity, and sexuality, and it should also be noted that benevolent sexism may also serve to justify hostile attitudes toward women (Glick \& Fiske, 1996). For example, and as we have suggested above, to the extent that the benevolent sexist idealized some types of women (e.g., women with large breasts), he may feel no hesitation about denigrating other types.

Our results also showed that a greater tendency to objectify women was associated with a greater likelihood of rating larger breasts as physically attractive. Previous scholars have argued that, in many socioeconomically developed societies, female breasts have become an important site of objectification of the female body (Seifert, 2005; Ward et al., 2006). This is evidenced, for example, in media aimed at hegemonic masculinities (Gerald \& Potvin, 2009), where large female breasts are fetishized and treated as sexual objects that fulfill the pleasures and desires of masculine men. In this view, the objectification of women's body parts, including though not limited to their breasts, is an example of the dominance of men over women and is further reproduced through cultural expectations of heteronormativity (Martino \& Pallotta-Chiarolli, 2005). Moreover, this normalization compels women to put up with the objectification of their breasts and bodies by men, and even to treat such objectification as flattering (Pascoe, 2007).

In addition to the above findings, we also found that most men $(32.7 \%)$ selected medium breasts as the most physically attractive. Large $(24.4 \%)$ and very large breasts $(19.1 \%)$ were also selected more frequently than either small $(15.5 \%)$ or very small $(8.3 \%)$ breasts. In general, these findings were comparable with recent studies (e.g., Zelazniewicz \& Pawłowski, 2010) that have used more ecologically valid sets of stimuli than early work that used line-drawings of the female form. Furthermore, as Zelazniewicz and Pawłowski have suggested, the use of a five-level scale when assessing breast size preferences allows us to overcome the limitations associated with stimuli that only vary along two dimensions (e.g., small versus large). Finally, the use of stimuli that rotated to provide a $360^{\circ}$ view overcomes limitations of static images, including the fact that viewing angle influences breast size perceptions (Zelazniewicz \& Pawłowski, 2010).

There were a number of shortcomings of the present work, which should be acknowledged. First, the faces of our stimuli 
were identical for each of the presented figures, a design issue we felt was necessary in order to minimize the impact of facial cues on participants' attractiveness ratings. Although participants may have focused more on the figures' bodies as a result (see Dixson et al., 2011), it may be useful for future research to concurrently examine the impact of facial and bodily cues on attractiveness judgments (Thornhill \& Grammer, 1999). In a similar vein, it may be useful to concurrently examine the impact of breast size and other characteristics associated with the breast specifically (e.g., shape, symmetry) and the body more generally (e.g., body size, waist-to-hip ratio, leg length). Aside from limitations of our stimulus set, it should also be noted that our method of recruitment, while allowing us to avoid a reliance on university students, means that our findings may not be generalizable to the wider community. Future studies would do well to recruit more representative samples and also to more carefully examine cross-cultural differences in breast size preference (Dixson et al., 2010). Finally, socially desirable responding may have affected our results: for example, it is possible that political correctness caused some men to report less interest in large breasts than they actually have (or, conversely, that a lack of concern for political concern resulted in some men more honestly reporting their preferences).

In summary, the results of the present study showed that men's oppressive beliefs predicted their idealization of larger female breasts. These results may have important implications for contemporary theorizing of breast size preferences. In addition to considering the distal evolutionary pressures that led to men's breast size preferences, our findings also highlight the importance of considering the proximate sociocultural context in which those judgments are made (cf. Little, Jones, DeBruine, \& Caldwell, 2011). Specifically, it seems clear that the lived experiences of women and men in contemporary societies, and particularly their gendered relations with one another, will have a major impact on their beauty ideals and practices (Forbes et al., 2007). More broadly, future research would do well to more carefully consider the ways in which such beauty ideals shape and maintain gendered divisions in contemporary societies.

\section{References}

Barber, N. (1995). The evolutionary psychology of physical attractiveness: Sexual selection and human morphology. Ethology and Sociobiology, 16, 395-424.

Bartky, S. L. (1990). Femininity and domination: Studies in the phenomenology of oppression. New York: Routledge.

Bordo, S. (1993). Unbearable weight: Feminism, western culture and the body. Berkeley, CA: University of California Press.

Buss, D. M. (2003). The evolution of desire (2nd ed.). New York: Basic Books.
Carter, P. (1996). Breast feeding and the social construction of heterosexuality, or 'What breasts are really for'. In J. Holland \& L. Adkins (Eds.), Sex, sensibility, and the gendered body (pp. 99-119). London: Macmillan.

Cornelissen, P.L., Hancock, P. J. B., Kiviniemi, V., George, H. R., \& Tovée, M. J. (2009). Patterns of eye movements when male and female observers judge female attractiveness, body fat, and waist-to-hip ratio. Evolution and Human Behavior, 30, 417-428.

Dettwyler, K. A. (1995). Beauty and the breast: The cultural context of breastfeeding in the United States. In P. MacAdam \& K. A. Dettwyler (Eds.), Breastfeeding: Biocultural perspectives (pp. 167-215). New York: De Gruyter.

Dixson, B. J., Grimshaw, G. M., Linklater, W. L., \& Dixson, A. F. (2011). Eye-tracking of men's preferences for waist-to-hip ratio and breast size of women. Archives of Sexual Behavior, 40, 43-50.

Dixson, B. J., Vasey, P. L., Sagata, K., Sibanda, N., Linklater, W. L., \& Dixson, A. F. (2010). Men's preferences for women's breast morphology in New Zealand, Samoa, and Papua New Guinea. Archives of Sexual Behavior, 40, 1271-1279.

Dworkin, A. (1974). Woman hating. New York: E. P. Dutton.

Einon, D. (2007). The shaping of women's bodies: Men's choice of fertility or heat stress avoidance? In V. Swami \& A. Furnham (Eds.), The body beautiful: Evolutionary and sociocultural perspectives (pp. 131-158). Basingstoke: Palgrave Macmillan.

Forbes, G. B., Collinsworth, L. L., Jobe, R. L., Braun, K. D., \& Wise, L. M. (2007). Sexism, hostility toward women, and endorsement of beauty ideals and practices: Are beauty ideals associated with oppressive beliefs? Sex Roles, 5, 265-273.

Forbes, G. B., Jobe, R. L., \& Revak, J. A. (2006). Relationships between dissatisfaction with specific body characteristics and the Sociocultural Attitudes Toward Appearance Questionnaire-3 and Objectified Body Consciousness Scale. Body Image, 3, 295-300.

Ford, C.S., \& Beach,F. A.(1951). Patterns of sexual behavior. New York: Harper.

Frederickson, B. L., Roberts, T. A., Noll, S. M., Quinn, D. M., \& Twenge, J. M. (1998). That swimsuit becomes you: Sex differences in selfobjectification, restrained eating, and math performance. Journal of Personality and Social Psychology, 75, 269-284.

Furnham, A., Dias, M., \& McClelland, A. (1998). The role of body weight, waist-to-hip ratio, and breast size in judgments of female attractiveness. Sex Roles, 39, 311-326.

Furnham, A., \& Swami, V. (2007). Perceptions of female buttocks and breast size in profile. Social Behavior and Personality, 35, 1-8.

Furnham, A., Swami, V., \& Shah, K. (2006). Female body correlates of attractiveness and other ratings. Personality and Individual Differences, 41, 443-454.

Gallup, G. G. (1982). Permanent breast enlargement in human female: A sociobiological analysis. Journal of Human Evolution, 19, 111-123.

Gerald, W., \& Potvin,L. (2009). Boobs, boxing, and bombs: Problematizing the entertainment of Spike TV. Spaces for Difference, 2, 3-14.

Gitter, A. G., Lomranz, J., Saxe, L., \& Bar-Tal, D. (1983). Perception of female physique characteristics by American and Israeli students. Journal of Social Psychology, 121, 7-13.

Glick, P., \& Fiske, S. T. (1996). The Ambivalent Sexism Inventory: Differentiating hostile and benevolent sexism. Journal of Personality and Social Psychology, 70, 491-512.

Gurung, R. A. R., \& Chrouser, C. J. (2007). Predicting objectification: Do provocative clothing and observer characteristics matter? Sex Roles, 57, 91-99.

Harrison, K. (2003). Television viewers' ideal body proportions: The case of the curvaceously thin woman. Sex Roles, 48, 255-264.

Hill, M. S., \& Fischer, A. R. (2008). Examining objectification theory: Lesbian and heterosexual women's experiences with sexual- and selfobjectification. The Counseling Psychologist, 36, 745-776. 
Horvath, T. (1981). Physical attractiveness: The influence of selected torso parameters. Archives of Sexual Behavior, 10, 21-24.

Jacobi, L., \& Cash, T. F. (1994). In pursuit of the perfect appearance: Discrepancies among self-ideal percepts of multiple physical attributes. Journal of Applied Social Psychology, 24, 379-396.

Kleinke, C. L., \& Staneski, R. (1980). First impressions of female bust size. Journal of Social Psychology, 110, 123-134.

Koff, E., \& Benavage, A. (1998). Breast size perception and satisfaction, body image, and psychological functioning in Caucasian and Asian American college women. Sex Roles, 38, 655-673.

Little, A. C., Jones, B. C., DeBruine, L. M., \& Caldwell, C. A. (2011). Social learning and human mate preferences: A potential mechanism for generating and maintaining between-population diversity in attraction. Philosophical Transaction of the Royal Society B, 366, 366-375.

Lonsway, K. A., \& Fitzgerald, L. F. (1995). Attitudinal antecedents of rape myth acceptance: A theoretical and empirical re-examination. Journal of Personality and Social Psychology, 68, 704-711.

Lynn, M. (2009). Determinants and consequences of female attractiveness and sexiness: Realistic tests with restaurant waitresses. Archives of Sexual Behavior, 38, 737-745.

Manning, J., Scutt, D., Whitehouse, G., \& Leinster, S. (1997). Breast asymmetry and phenotypic quality in women. Evolution and Human Behavior, 18, 223-236.

Marlowe, F. (1998). The nubility hypothesis: The human breast as an honest signal of residual reproductive value. Human Nature, 9, 263-271.

Martino, W., \& Pallotta-Chiarolli, M. (2005). "Being normal is the only way to be": Adolescents perspectives on gender and school. Sydney: University of New South Wales Press.

Mazur, A. (1986). US trends in feminine beauty and overadaptation. Journal of Sex Research, 22, 281-303.

Millsted, R., \& Frith, H. (2003). Being large-breasted: Women negotiating embodiment. Women's Studies International Forum, 26, 455-465.

Pascoe, C. J. (2007). Dude, you're a fag: Masculinity and sexuality in high school. Berkeley, CA: University of California Press.

Pawłowski, B. (1999). Permanent breasts as a side effect of subcutaneous fat tissue increase in human evolution. Homo, 50, 149-162.

Pond, C. M. (1998). The fats of life. New York: DK Publishing.

Rhodes, G. (2006). The evolutionary psychology of facial beauty. Annual Review of Psychology, 57, 199-226.

Salska, I., Frederick, D. A., Pawłowski, B., Reilly, A. H., Laird, K. T., \& Rudd, N. A. (2008). Conditional mate preferences: Factors influencing preferences for height. Personality and Individual Differences, 44, 203-215.

Sanchez,D. T., Kiefer, A. K., \& Ybarra, O. (2006). Sexual submissiveness in women: Costs for sexual autonomy and arousal. Personality and Social Psychology Bulletin, 32, 512-524.

Seifert, T. (2005). Anthropomorphic characteristics of centerfold models: Trends towards slender figures over time. International Journal of Eating Disorders, 37, 271-274

Singh, D., \& Young, R. K. (1995). Body weight, waist-to-hip ratio, breast size, and hips: Role in judgments of female attractiveness and desirability for relationships. Ethology and Sociobiology, 16, 483-507.

Smith, K. L., Cornelissen, P. L., \& Tovée, M. J. (2007). Color 3D bodies and judgments of human female attractiveness. Evolution and Human Behavior, 28, 48-54.

Spence, J. T., Helmreich, R., \& Stapp, J. (1978). A short version of the Attitudes toward Women Scale (AWS). Bulletin of the Psychonomic Society, 2, 219-220.

Strelan, P., \& Hargreaves, D. (2005). Women who objectify other women: The vicious cycle of objectification. Sex Roles, 52, 707-712.

Swami, V. (2007). The missing arms of Vénus de Milo: Reflections on the science of physical attractiveness. Brighton: Book Guild.

Swami, V. (2008). Methodological and conceptual issues in the science of physical attraction. In I. L. Nillson \& W. V. Lindberg (Eds.), Visual perception: New research (pp. 232-256). Hauppauge, NY: Nova Science Publishers.
Swami, V. (2011). Love at first sight? Individual differences and the psychology of initial romantic attraction. In T. Chamorro-Premuzic, $S$. von Stumm, \& A. Furnham(Eds.), Handbook of individual differences (pp. 747-772). Oxford: Wiley-Blackwell.

Swami, V., \& Barrett, S. (2011). British men's hair colour preferences: An assessment of courtship solicitation and stimulus ratings. Scandinavian Journal of Psychology, 52, 595-600.

Swami, V., Buchanan, T., Furnham, A., \& Tovée, M. J. (2008a). Five-factor personality correlates of perceptions of women's body sizes. Personality and Individual Differences, 45, 697-699.

Swami, V., Coles, R., Salem, N., Wilson, E., Wyrozumska, K., \& Furnham, A. (2010a). Oppressive beliefs at play: Associations among beauty ideals and practices and individual differences in sexism, objectification of others, and media exposure. Psychology of Women Quarterly, $34,365-379$.

Swami, V., Einon, D., \& Furnham, A. (2006). An investigation of the leg-tobody ratio as a human aesthetic criterion. Body Image, 3, 317-323.

Swami, V., \& Furnham, A. (2008). The psychology of physical attraction. London: Routledge.

Swami, V., Furnham, A., Balakumar, N., Williams, C., Canaway, K., \& Stanistreet, D. (2008b). Factors influencing preferences for height: A replication and extension. Personality and Individual Differences, 45 , 395-400.

Swami, V., Furnham, A., Chamorro-Premuzic, T., Akbar, K., Gordon, N., Harris, T.,...,Tovée, M. J. (2010b). More than skin deep? Personality information influences men's ratings of the attractiveness of women's body sizes. The Journal of Social Psychology, 150, 628-647.

Swami, V., \& Harris, A. S. (2012). Evolutionary perspectives on physical appearance. In T. Cash (Ed.), Encylopedia of body image and human appearance (pp. 404-411). Oxford, UK: Elsevier.

Swami, V., Jones, J., Einon, D., \& Furnham, A. (2009). Men's preferences for women's profile waist-to-hip ratio, breast size, and ethnic group in Britain and South Africa. British Journal of Psychology, 100, 313325.

Swami, V., Miller, R., Furnham, A., Penke, L., \& Tovée, M. J. (2008c). The influence of men's sexual strategies on perceptions of women's bodily attractiveness, health and fertility. Personality and Individual Differences, 44, 98-107.

Swami, V., \& Salem, N. (2011). The evolutionary psychology of human beauty. In V. Swami (Ed.), Evolutionary psychology: A critical introduction (pp. 131-182). Oxford: Wiley-Blackwell.

Swami, V., \& Tovée, M. J. (2009). Big beautiful women: The body size preferences of male fat admirers. Journal of Sex Research, 46, 89-96.

Swami, V., \& Voracek, M. (in press). Associations among men's sexist attitudes, objectification of women, and their own drive for muscularity. Psychology of Men and Masculinity.

Tantleff-Dunn, S. (2001). Breast and chest size: Ideals and stereotypes through the 1990 s. Sex Roles, 45, 231-242.

Tantleff-Dunn, S. (2002). Biggest isn't always best: The effect of breast size on perceptions of women. Journal of Applied Social Psychology, 32, $2253-2265$.

Tantleff-Dunn, S., \& Thompson, J. K. (2000). Breast and chest size satisfaction: Relation to overall body image and self-esteem. Eating Disorders, 8, 241-246.

Thompson, E. H., Pleck, J. H., \& Ferrera, D. L. (1992). Men and masculinities: Scales for masculinity ideology and masculinity-related constructs. Sex Roles, 27, 573-607.

Thornhill, R., \& Grammer, K. (1999). The body and face of woman: One ornament that signals quality? Evolution and Human Behavior, 20, $105-120$.

Tovée, M. J., \& Cornelissen, P. L. (2001). Female and male perceptions of female physical attractiveness in front-view and profile. British Journal of Psychology, 92, 391-402.

Ward, L. M., Merriwether, A., \& Caruthers, A. (2006). Breasts are for men: Media, masculinity ideologies, and men's beliefs about women's bodies. Sex Roles, 55, 703-714. 
Wiggins, J. S., Wiggins, N., \& Conger, J. C. (1968). Correlates of heterosexual somatic preference. Journal of Personality and Social Psychology, $10,82-90$.

Wolf, N. (1990). The beauty myth. London: Chatto \& Windus.
Zelazniewicz, A. M., \& Pawłowski, B. (2010). Female breast size attractiveness for men as a function of sociosexual orientation (restricted versus unrestricted). Archives of Sexual Behavior, 40, 1129-1135. 